\title{
An approach to the implementation of European Directive 2007/60/EC on flood risk management in the Czech Republic
}

\author{
A. Dráb and J. Říha \\ Water Structures Institute, FCE, Brno University of Technology, Brno, Czech Republic \\ Received: 9 June 2009 - Revised: 8 July 2010 - Accepted: 4 August 2010 - Published: 24 September 2010
}

\begin{abstract}
Directive 2007/60/EC of the European Parliament and of the Council of 23 October 2007 on the assessment and management of flood risks (the Flood Risk Directive) signifies that flood risk analysis methods are gaining ground in EC Member States and, therefore, also in the Czech Republic (CR). Procedures of flood risk analysis have been developed in the Czech Republic since the catastrophic floods of 1997 in line with European and worldwide trends and have been tested and applied in hundreds of case studies to date. Currently, the Flood Risk Directive Guideline based on past experience with flood risk analysis applications is being processed.

The aim of the paper is to present flood risk analysis procedures and specially developed techniques for the assembly of flood hazard, danger and flood risk maps. Methods related to flood risk management plans are briefly mentioned as well. The following particular problems are discussed in more detail: an application and extension of the "danger matrix" approach, the definition of residual danger, the formulation of efficiency criteria and preliminary multi-criteria flood risk assessment. These issues were tested in practical applications at pilot locations in the Czech Republic. Present experience provides evidence that the flood risk analysis methods used in the Czech Republic are in harmony with the requirements of the Flood Risk Directive. The proposed and applied methods are based primarily on existing available data such as flood extent maps, cadastral maps, the Register of Census Districts and Structures and others.
\end{abstract}

\section{Introduction}

Experience from extreme flood events in the Czech Republic during recent years has shown the necessity for a systematic approach to flood protection. Procedures based on the

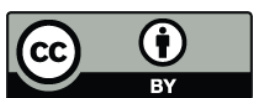

Correspondence to: A. Dráb (drab.a@fce.vutbr.cz) theory of risk management appear to be very effective for this purpose. The technical issues related to flood risk analysis have been studied by numerous authors (Klijn et al., 2008; Schanze et al., 2008; Hutter, 2007; Alphen and Passchier, 2007; Samuels et al., 2006).

Above all, these methods enable the identification of endangered areas and the consecutive, effective design of flood protection measures (FPMs). FPM conception should be based on effectiveness and efficiency assessment (Schanze et al., 2008). For integrated flood risk assessment the multicriteria approach can be applied (Meyer et al., 2007, 2009; Kubal et al., 2009).

The Flood Risk Directive (ES, 2007) is calling for the development of effective tools for appointing priorities in the taking of technical, financial and political decisions in flood risk management. The Flood Risk Directive requires three stages of flood risk management (see details in Sect. 2):

1. Preliminary flood risk assessment.

2. Creation of flood hazard and risk maps for various scenarios.

3. Development of flood risk management plans.

The Flood Risk Directive only defines general requirements for these three stages. Member states themselves decide on the appropriate methods needed for its implementation as geographical, hydrological and social differences demand specific approaches. Therefore, the working group on floods (WGF) was established in 2007 primarily to support the implementation of the Flood Risk Directive. The WGF provides a platform for the exchange of information through a series of thematic workshops addressing particular issues on the Flood Risk Directive to help member states with the implementation process (WGF, 2007).

The terminology of flood risk analysis is still not uniform worldwide and also not within Europe. In this paper, terminology according to Gouldby and Samuels (2005) and ES (2007) has been used. The authors of this text follow

Published by Copernicus Publications on behalf of the European Geosciences Union. 
the concepts of hazard, exposure and vulnerability as components of flood risk. However, a few additional terms have been introduced and defined, namely in the context of the matrix for the "danger" classification (Zimmerman et al., 2005; FOWM, 1997) (see Sect. 2.2). In this context, danger is understood as a convolution of hazard and exposure and is expressed by means of danger maps.

In our study, we focus on the process of implementing the Flood Risk Directive in the Czech Republic. Particular methods corresponding to the three above-mentioned stages of flood risk management are described in the text together with a discussion of particular issues which were faced during the implementation process. It is essential that the flood risk assessment methods in the Czech Republic are founded on existing and well-established data and procedures. This prerequisite principle has resulted in the necessity of modifying and adapting existing techniques, e.g. the "danger matrix" approach, to define residual danger and to formulate efficiency criteria.

The objectives of the paper are to introduce the philosophy of Flood Risk Directive implementation in the Czech Republic and to present the way in which the general requirements have been met. More information is given about the preliminary flood risk assessment method, flood hazard and risk map compilation for the given set of flood return periods, and also about the development of flood risk management plans using economic efficiency criteria and multi-criteria assessment techniques. The procedures are demonstrated in a case study within the municipal area of the city of Brno. The paper is structured as follows: after introducing its aims in Sect. 1, the three stages of Flood Risk Directive implementation are presented in Sect. 2, which is the most comprehensive part of the text. Section 3 is concerned with the case study. The conclusions and specifications for further research are in Sect. 4.

\section{Implementation of Flood Risk Directive 2007/60/ES in the $\mathbf{C R}$}

During the implementation of the Flood Risk Directive (ES, 2007), currently used flood risk assessment methods will be employed. At present it is planned that a detailed description of these methods will be part of the Guidelines (MA CR, 2009) which have recently been elaborated (see the following sections).

\subsection{Preliminary flood risk assessment}

The aim of preliminary flood risk assessment is the definition of areas where more detailed risk-based methods should be applied. The Flood Risk Directive requires an assessment of the unfavourable consequences of significant floods which have occurred in the past, and of potential future floods. It was proposed by authors of this text, in accordance with this requirement, that the initial basis for preliminary flood risk assessment would be existing documentation. The basis for the floodplain protection issues in the Czech Republic are what are known as flood extent maps developed and maintained according to legislative instructions (MV CR, 2002, 2001). In the CR, floodplains are defined as administratively determined areas which can be inundated during a flood event. Floodplain boundaries are demarcated for maximum water levels on the basis of hydraulic calculations, documentation from extreme past flood events or alluvial soil areas.

The existing flood documentation according to MV CR (2002) contains flood scenarios corresponding to return periods of 5, 20 and 100 years $\left(Q_{5}, Q_{20}, Q_{100}\right)$. Extreme historical flood extents and the extents of dam break floods are displayed on the maps as well.

In some cases, so-called "active zones" are demarcated in the existing floodplain documentation according to MV CR (2001). These sub-areas in the floodplain represent zones with high hazard and extensive flood damage potential (high flow velocity, water depth, etc.). At present, the "active zones" approach is being replaced by flood risk analysis methods according to the Flood Risk Directive (ES, 2007) (see Sect. 2.2). Nowadays, floodplain boundaries are available as an element of thematic maps (Flood extent maps 1:10 000) (T.G.M. WRI, 2009). Generally available floodplain documentation serves as fundamental information:

- as a decision-making tool for governmental institutions,

- for urban planning,

- in the design of flood protection measures (structures),

- for flood emergency plans.

These documents provide a starting point for preliminary risk assessment in the area of interest and for the demarcation of watercourses in the Czech Republic with potential significant flood risk. The following aspects have been considered:

- the number of residents in the floodplain area,

- the property in the urbanised areas,

- pollution sources,

- transport infrastructure.

The necessary data were taken from the Register of Census Districts and Structures (CSO, 2009) and ZABAGED (COSMC, 2009). By combining the aforementioned aspects using GIS techniques it was possible to preliminarily estimate the endangered property and the number of affected inhabitants in existing areas with the potential for flooding (Drbal and Štěpánková, 2008). Based on the preliminary assessment, a list of the most endangered areas where more detailed risk analysis is needed has been created. The procedure resulted in the identification of $2494 \mathrm{~km}$ of watercourses in the $\mathrm{CR}$ which have high flood risk potential and for which more detailed evaluation is proposed (see Fig. 1). 

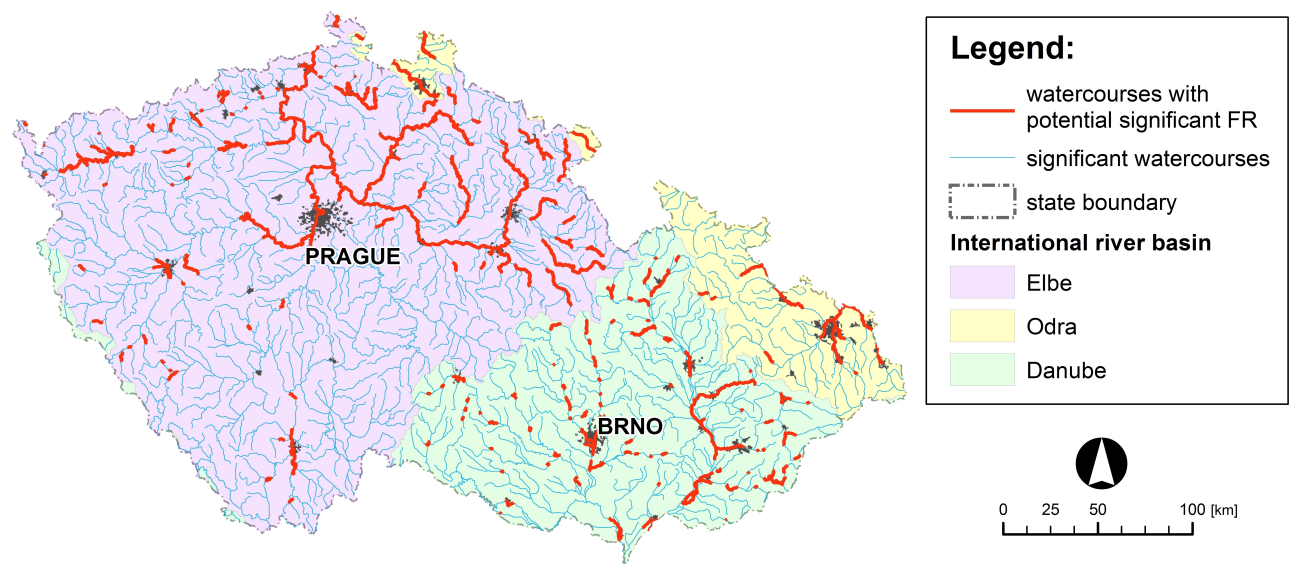

Fig. 1. Selected watercourses in the CR which have high flood risk (FR) potential and for which more detailed evaluation is proposed (Drbal and Štěpánková, 2008).

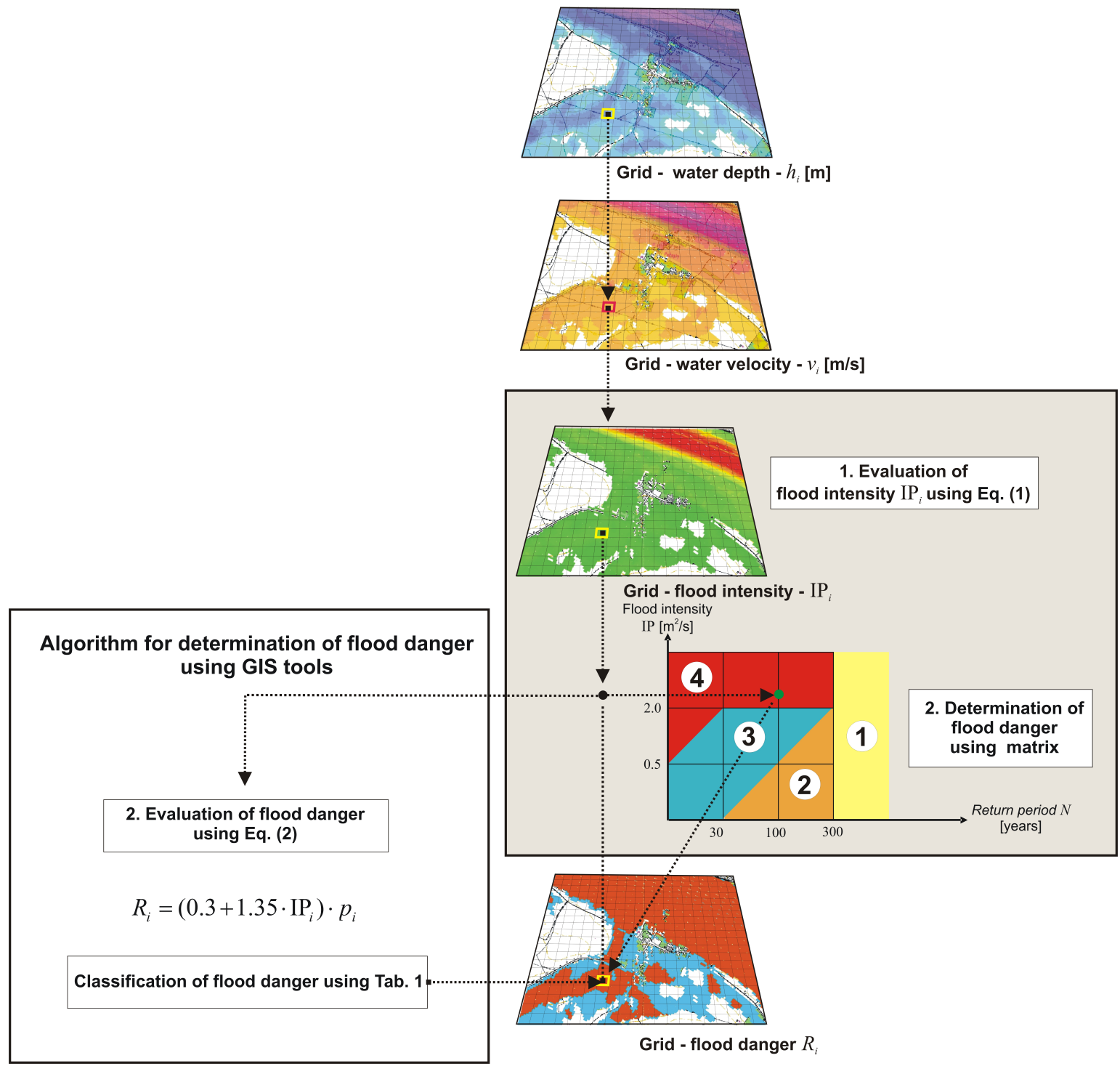

Fig. 2. Flow chart for the development of flood hazard and flood danger maps for a given flood scenario (peak discharge). 


\subsection{Flood hazard maps and flood risk maps}

The second stage in the Flood Risk Directive implementation is the creation of flood hazard and risk maps for various flood scenarios corresponding to low, medium and high probability. For the construction of the danger and risk maps a semi-quantitative method has been proposed based on a matrix for the determination of the danger level (Zimmerman et al., 2005) which serves the purpose for the spatial evaluation of corresponding quantities. The procedure originates from the Swiss method (FOWM, 1997), adapted and tested for the conditions in the Czech Republic. In the context of the matrix approach the concept "flood danger" - exposure to hazard - is introduced in the following text. The authors applied the following steps (see Fig. 2):

1. the quantification of flood hazard via hydraulic calculations and the evaluation of flood intensity IP (FOWM, 1997),

2. determination of exposure to flood hazard using the "danger matrix" (Zimmerman et al., 2005; de Moel et al., 2009),

3. the construction of flood risk maps by combining flood danger with the vulnerability of the area.

In the first step, the flood hazard is expressed in terms of what is known as flood intensity IP. This is understood to be a measure of the destructive ability of a flood and is defined as a function of water depth $h$ and velocity $v$. Using previously carried out experiments and expert assessment (FOWM, 1997) the flood intensity is expressed as follows:

$\operatorname{IP}(h, v)=\left\{\begin{array}{rr}0, & h=0 \\ h, & h>0 \mathrm{~m}, v \leq 1 \mathrm{~m} / \mathrm{s} \\ h . v, & v>1 \mathrm{~m} / \mathrm{s}\end{array}\right\}$.

The flood hazard maps (maps of water depth and velocity) have to be primarily developed using existing flood extent maps based on previously performed hydraulic calculations (see Sect. 2.1). The majority of older studies used a onedimensional hydraulic model; only a few were performed with the use of two-dimensional steady-state models. The crucial problems with the use of existing flood extent maps are as follows:

- existing flood extent maps have usually been prepared for flood scenarios corresponding with return periods of 5,20 and 100 years $\left(Q_{5}, Q_{20}, Q_{100}\right)$ as required by current Czech legislation (MV CR, 2002). Therefore, the flood extent maps do not include the scenario defined by the Flood Risk Directive (ES, 2007) "for floods with a low probability or extreme event scenarios". In the CR this scenario is defined as the $Q_{500}$ discharge, for which further hydraulic calculations are required,
- flood extent maps do not generally contain information on water depth, which has to be subsequently evaluated using GIS tools. Usually, the information about flow velocity is not adequate or is completely missing.

Solving the above-mentioned problems is easier in cases where an updated hydrodynamic model is available. This allows the additional calculation of the $Q_{500}$ scenario, and also the completion of missing data on water depths and velocities. For more significant watercourses in the CR, hydrodynamic models maintained by river authorities are available.

Based on the calculated flood intensity IP from Eq. (1), the flood danger is evaluated using the so-called "danger matrix" (see Fig. 2). Appropriate recommendations according to Table 1 are taken into account during the determination of such derived hazard values. In the Czech Republic the method described is applied to the relevant flood scenarios: $Q_{5}, Q_{20}$, $Q_{100}, Q_{500}$. The resulting danger level is assumed to be the maximum danger level obtained in individual flood scenarios according to Eq. (5).

The procedure using the "danger matrix" (right side in Fig. 2) represents a conceptual approach to the problem and can be used in the case of manual interpretation of the method. Today, the procedure is algorithmized using GIS tools, thus, enabling the processing of digital maps and the final numerical evaluation of flood intensity and danger. For this reason, the flood danger $R$ is defined as a product of the exposure represented by the exceedance probability $p$ of a flood scenario and the hazard represented by flood intensity IP (see Eq. 2) (Beffa, 2000). The corresponding maps developed according to Fig. 2 then express the flood danger across the whole floodplain regardless of the land use.

The flood danger $R_{i}$ for a given flood scenario $i$ with the exceedance probability $p_{i}$ and a return period of $N_{i}$ years is obtained by recalculating the boundaries of danger zones in the "danger matrix" (Fig. 2, Table 1). The following formula holds (Beffa, 2000):

$R_{i}=\left(0.3+1.35 \cdot \mathrm{IP}_{i}\right) \cdot p_{i}$,

where the exceedance probability $p$ of flood scenario $i$ can be expressed as follows:

$p_{i}=1-e^{-\frac{1}{N_{i}}}$.

For $N_{i} \geq 5$ the relation (3) can be approximated by:

$p_{i} \approx \frac{1}{N_{i}}$,

The resulting local danger $R$ is expressed as the maximum value of the individual dangers $R_{i}$ corresponding to flood scenarios represented by the return period $N_{i}$ :

$R=\max _{i=1}^{n} R_{i}$,

where $n$ denotes the number of assessed flood scenarios. The obtained flood danger values $R$ are classified according to Table 1. 
Table 1. Danger classification and verbal description consistent with (Zimmerman et al., 2005; FOWM, 1997).

\begin{tabular}{|c|c|c|}
\hline $\begin{array}{c}\text { Danger level } R \\
\text { according to } \\
\text { Beffa (2000) } \\
\text { determined } \\
\text { from Eq. (2) }\end{array}$ & $\begin{array}{l}\text { Danger level* } \\
\text { determined from } \\
\text { the matrix } \\
\text { (see Fig. 2) }\end{array}$ & Recommendation \\
\hline $\begin{array}{l}R \geq 0.1 \text { or } \\
\mathrm{IP} \geq 2\end{array}$ & $\begin{array}{l}\text { (4) High } \\
\text { (red) }\end{array}$ & $\begin{array}{l}\text { Do not permit new or extend existing built up areas intended for people or animals. } \\
\text { It is necessary to put forward designs for flood protection measures for existing buildings } \\
\text { in order to attain an acceptable risk level. }\end{array}$ \\
\hline $0.01 \leq R<0.1$ & $\begin{array}{l}\text { (3) Medium } \\
\text { (blue) }\end{array}$ & $\begin{array}{l}\text { New construction is possible with restrictions based on detailed assessment of potential flood } \\
\text { hazards for buildings. The location of sensitive structures, such as hospitals, fire departments, } \\
\text { etc., in this area is unsuitable. The expansion of current built-up areas is not recommended. }\end{array}$ \\
\hline$R<0.01$ & $\begin{array}{l}\text { (2) Low } \\
\text { (orange) }\end{array}$ & $\begin{array}{l}\text { Construction is possible but land parcel owners must be warned of the potential flood hazard. } \\
\text { It is necessary to employ special flood measures for sensitive buildings. }\end{array}$ \\
\hline $\begin{array}{l}p<0.0033^{* *} \\
\quad(N>300)\end{array}$ & $\begin{array}{l}\text { (1) Residual } \\
\text { (yellow) }\end{array}$ & $\begin{array}{l}\text { It is recommended that questions associated with flooding be solved by means of urban } \\
\text { planning, taking into account sensitive structures (health care institutions, fire departments, } \\
\text { historical landmarks, etc.) and other structures with high vulnerability to flood damage. }\end{array}$ \\
\hline
\end{tabular}

* The danger category in conjunction with land use information (Table 2) and accepted recommendations represents an acceptable level of flood risk.

** Residual danger level is determined regardless of the $R$ value. Residual danger is represented by floods with very low exceedance probability.

The specific problem was the definition and delimitation of sub-regions with so-called "residual danger". The extent of real past extreme floods with high return periods (e.g. $N>300$ ) was the basis for the estimation of the residual danger area (note: in the context of ES, 2007 these scenarios are defined as "floods with low exceedance probability, or extreme event scenarios"). Furthermore, the alluvial floodplain morphology and the extent of alluvial loams in the area were taken into account. In the case of dams located upstream of the area of interest, the surface inundated by a potential dam break flood was also taken into account. The outer envelope of the flood extents mentioned above has been defined as the "residual danger" zone in danger maps. The proposed residual danger areas have to be verified by site investigations and comparison with a digital terrain model. Research has proven that there is conformity between the mentioned approaches for most of the areas studied.

The results of the described analysis in the area of interest are maps of flood danger maps (see examples in Sect. 3). The maps of flood danger, which are not strictly recommended by (ES, 2007) but are a necessary intermediate step at the procedure, express levels of flood danger and endangered areas using a colour spectrum supplemented by explanations according to Table 1 . To categorize the danger enables the assessment of the suitability of existing or planned land use and the recommendation of restrictions on activities or on the development of corresponding areas with higher danger rates. From this point of view, the danger maps completed with regard to recommendations according to Table $1 \mathrm{can}$ be assumed to be maps of acceptable risk. The method described can be used in the process of urban planning, during the preliminary proposals for flood protection measures, etc.
Table 2. An example of selected land use zones (MA CR, 2009).

\begin{tabular}{lc}
\hline Land use & Acceptable risk \\
\hline Residential & \\
Public services & (2) Low \\
Transportation and utility & \\
Industrial and manufacturing & \\
Agriculture & (3) Medium \\
Sport and recreation & \\
Water area & (4) High \\
Parks and open spaces, gardens, woods & \\
Arable land, meadows, pasture land & \\
\hline
\end{tabular}

Risk maps combine data about danger and vulnerability in the exposed area. The vulnerability data can be derived from urban plans and maps, and should be verified by site investigation. Based on the available urban plans, it is possible to define classes of land use (Table 2 - column "Land use"). Uniform classification is a completely new approach in the $\mathrm{CR}$ and it required great effort to find a compromise and negotiate towards it with urban planners.

A value of maximum acceptable risk is assigned to each class according to Table 2 - column "Acceptable risk". The maps of the areas, therefore, classified according to land use (vulnerability maps) are "overlaid" by danger maps and are processed by GIS analytical tools into risk maps in which existing or anticipated areas with exceeded acceptable risk are highlighted using a spectrum corresponding to Table 1 . The following logical step is a more detailed analysis of "risky areas" from the point of view of risk management and risk attenuation to an acceptable level. 
The described method using tailor-made software tools for GIS applications has been elaborated, tested and applied in the CR since the year 2001 at about 25 municipalities which contain more than $400 \mathrm{~km}$ of watercourses.

\subsection{Flood risk management plans}

The Flood Risk Directive requires that Member States establish flood risk management plans on the basis of hazard and risk maps. Flood risk management plans are primarily focused on prevention, protection and preparedness.

During the development of flood risk management plans, existing hydraulic and feasibility studies are used as basic documents. Hydraulic studies provide more detailed data in comparison with floodplain documentation. Their aim is the comprehensive assessment of flood protection in a given area and the indication of the course design floods could take. Hydraulic studies usually contain recommendations regarding variants of appropriate structural flood protection measures (FPMs) and assessments of their efficiency. On a more detailed level are feasibility studies which, in comparison with hydraulic studies, focus on more detailed technical solutions and on cost estimates for FPMs. Feasibility studies are often used as part of applications for financial allocations and are based on the elaboration of more detailed designs. FPMs are involved to the same extent in general water management audits and plans for urban areas. To date, the following risk-based methods have been implemented in the $\mathrm{CR}$ in the studies mentioned:

- the matrix for danger level determination (Zimmerman et al., 2005; FOWM, 1997) is being used for the assessment of floodplains from the viewpoint of flood hazard, vulnerability and risk (see Sect. 2.2). The method enables the general identification of areas and structures where the acceptable risk has been exceeded and following on from this, the design of flood protection measures,

- the method based on flood loss estimates described below serves for an assessment of the economic efficiency of structural FPMs. For the estimation of flood losses the available geographical data (COSMC, 2009) and data from the Census District and Building Register (CSO, 2009) are employed.

In accordance with the requirements of the Flood Risk Directive, the processing of flood risk management plans stems from the results of spatial analysis using the matrix method (Sect. 2.2) in which recommendations for further analysis and flood protection in areas with exceeded acceptable risk are introduced. For the complex assessment of FPM variants according to (ES, 2007), economic, environmental and social viewpoints are taken into account. For this purpose, multi-criteria analysis (MCA) is frequently used. At present, the evaluation of the economic effectiveness of FPMs is elaborated in detail while the risk-based analysis relating to other loss categories is still subject to research activities. Therefore, in the following text the category of economic losses is discussed in more details, while MCA, including other categories, is mentioned briefly at the end of this chapter.

In the case of the evaluation of the economic effectiveness of FPMs, the following steps are followed:

1. estimation of the extent of endangered and protected property in the floodplain,

2. estimation of flood losses,

3. quantification of flood risk using potential losses,

4. determination of quantitative economic criteria using cost benefit analysis.

The endangered property in the floodplain is estimated for the existing state and for the state after the implementation of flood protection measures. Firstly, the processing of flood hazards is carried out for flood scenarios corresponding with at least the $Q_{5}, Q_{20}$ and $Q_{100}$ discharges. The estimation of flood damage to property in the floodplain is performed using so-called damage functions which express the relation between water depth and the percentage of damage. The damage functions were developed and tested for the floods in the years 1997, 1998 and 2002 within the framework of prior research (Drbal et al., 2006) and were published as part of MA CR (2009) for the following elements of risk: residential buildings, service buildings, industrial buildings, roads, railways, bridges, paved areas, infrastructure, sport and recreation areas, farmland, forest land. For each element of risk the economic value of assets is estimated based on official statistical data (CSO, 2009). Material flood losses in monetary units are obtained by multiplying the economic value of assets and the corresponding percentage of damage (see Fig. 4). The total potential economic flood loss $D$ for a given flood scenario with exceedance probability $p$ is calculated by summarizing the losses across all elements in the analysed flooded area. Based on the potential flood losses $D$ the economic flood risk is expressed as follows (Říha et al., 2005):

$\mathrm{RI}=\int_{0}^{p_{\mathrm{H}}} D(p) d p$,

where RI is the economic flood risk in monetary units (CZK, EUR, .../yr.), $p$ is the exceedance probability of the corresponding $N$-year peak flood discharge determined by Eqs. (3) or (4), $D(p)$ represents the functional dependence of potential losses (CZK, EUR, etc.) on flood exceedance probability $p$ and $p_{\mathrm{H}}$ is the exceedance probability of harmless flood discharge which depends on the flood protection level in the area. The dependence (6) is derived from the potential losses estimated for individual flood scenarios. A geometrical interpretation of the integral (6) is shown in Fig. 3. 


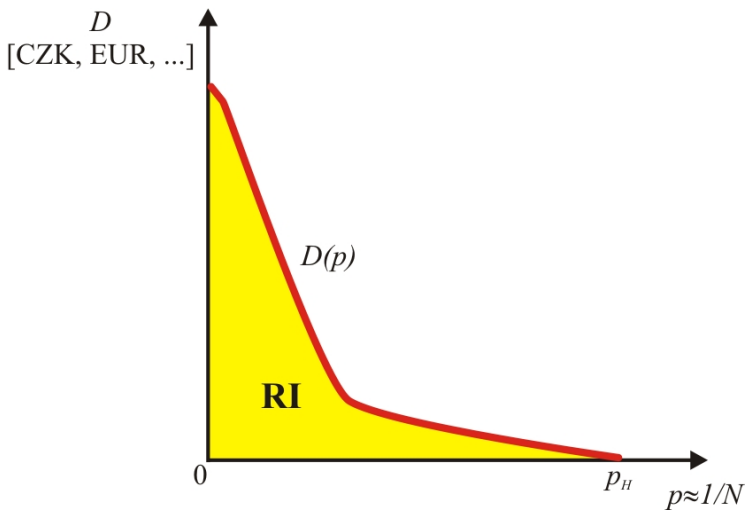

Fig. 3. Scheme of a flood loss exceedance curve $D(p)$.

A practical procedure for the calculation of average annual economic risk has been proposed as follows (see Fig. 4):

- the exceedance probability for individual flood scenarios represented by selected $N$-year flood discharges is estimated using Eqs. (3) or (4),

- the hydraulic characteristics of the flood, namely water depth, are determined by hydraulic modelling of the flow in related watercourses, including the floodplain,

- the direct economic losses in the area of interest are derived using the damage curves (MA CR, 2009) from the hydraulic characteristics for selected flood scenarios. A graphical interpretation of the obtained function $D(p)$ can be seen in Fig. 3,

- the numerical integration of Eq. (6) gives an estimate of the annual average risk.

The method described was implemented into GIS using a tailor-made application eliminating the routine manual rerunning of individual procedures. A flow chart of the procedure related to a given flood scenario is shown in Fig. 4.

The final value of RI serves for the evaluation of the economic efficiency of proposed variants of structural flood protection measures. The following indicators $(\mathrm{RE}-\mathrm{re}-$ lative efficiency, AE - absolute efficiency, RP - repayment period) were proposed for the cost-benefit analysis (Říha et al., 2005; MA CR, 2006):

$$
\begin{aligned}
\mathrm{RE} & =\frac{\mathrm{RI}_{\mathrm{ORIG}}-\mathrm{RI}_{\mathrm{NEW}}}{I \cdot \mathrm{DR}}, \\
\mathrm{AE} & =\left(\frac{\mathrm{RI}_{\mathrm{ORIG}}-\mathrm{RI}_{\mathrm{NEW}}}{\mathrm{DR}}\right)-I, \\
\mathrm{RP} & =\frac{I}{\mathrm{RI}_{\mathrm{ORIG}}-\mathrm{RI}_{\mathrm{NEW}}}
\end{aligned}
$$

where $\mathrm{RI}_{\mathrm{ORIG}}$ and $\mathrm{RI}_{\mathrm{NEW}}$ are average annual economic risks before and after the application of flood protection measures,

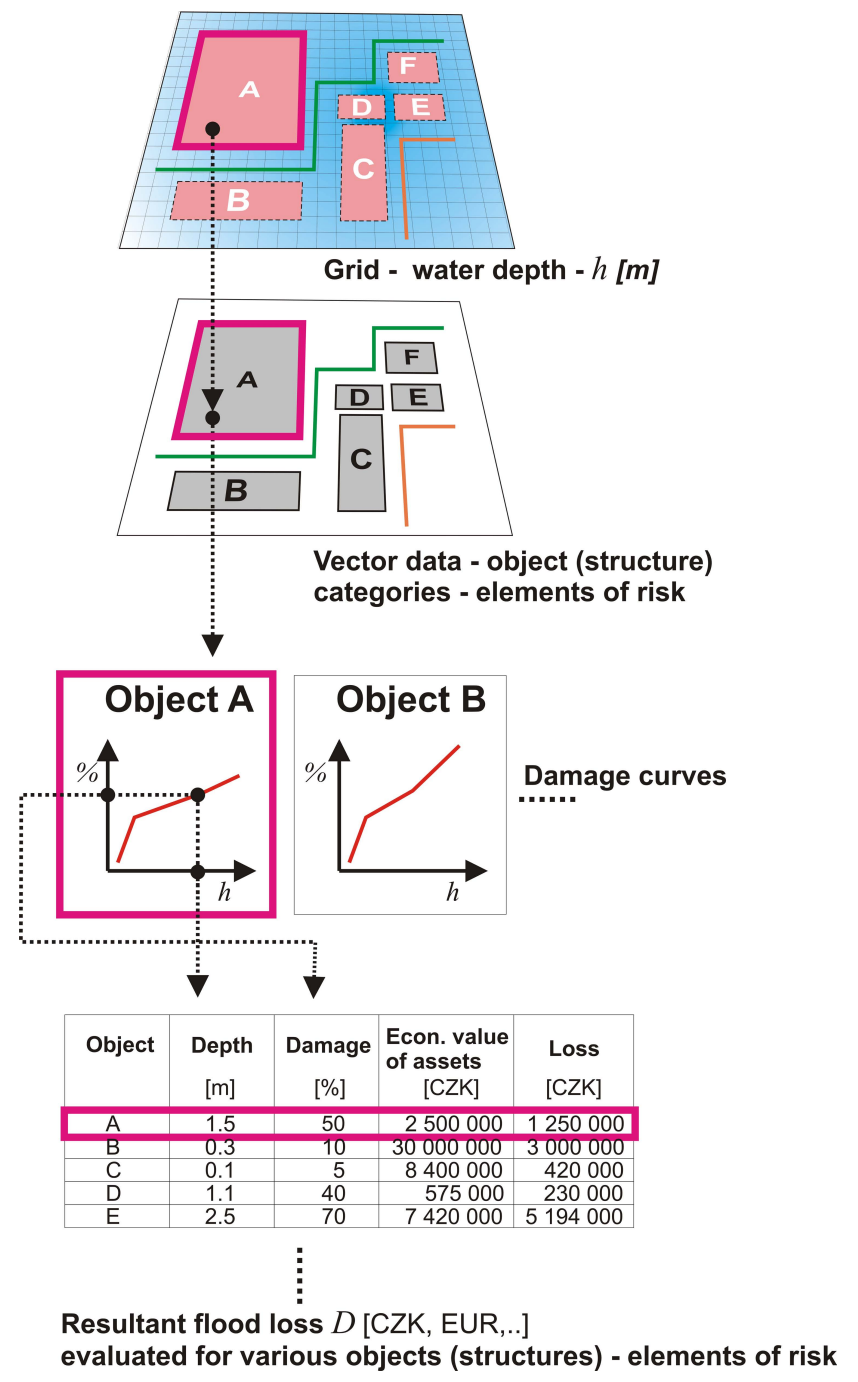

Fig. 4. Flow chart for the evaluation of potential flood loss using GIS.

$I$ is the investment cost and DR is the discount rate. The flood protection arrangements are profitable if $\mathrm{RE}>1$; the economic efficiency increases with increasing $\mathrm{AE}$ and with decreasing RP.

The method described has been widely applied in the assessment of hundreds of anticipated flood protection measures financed from the funds of the European Investment Bank within the framework of the project (MA CR, 2006). During this assessment the economic risk was the only criterion.

According to ES (2007), the flood protection measures and their sub-sections related to individual areas should be prioritized using multi-criteria analysis during which other important partial risks are taken into account. For the flood risk management plans in the Czech Republic the partial risks $\mathrm{RI}_{i}$ 


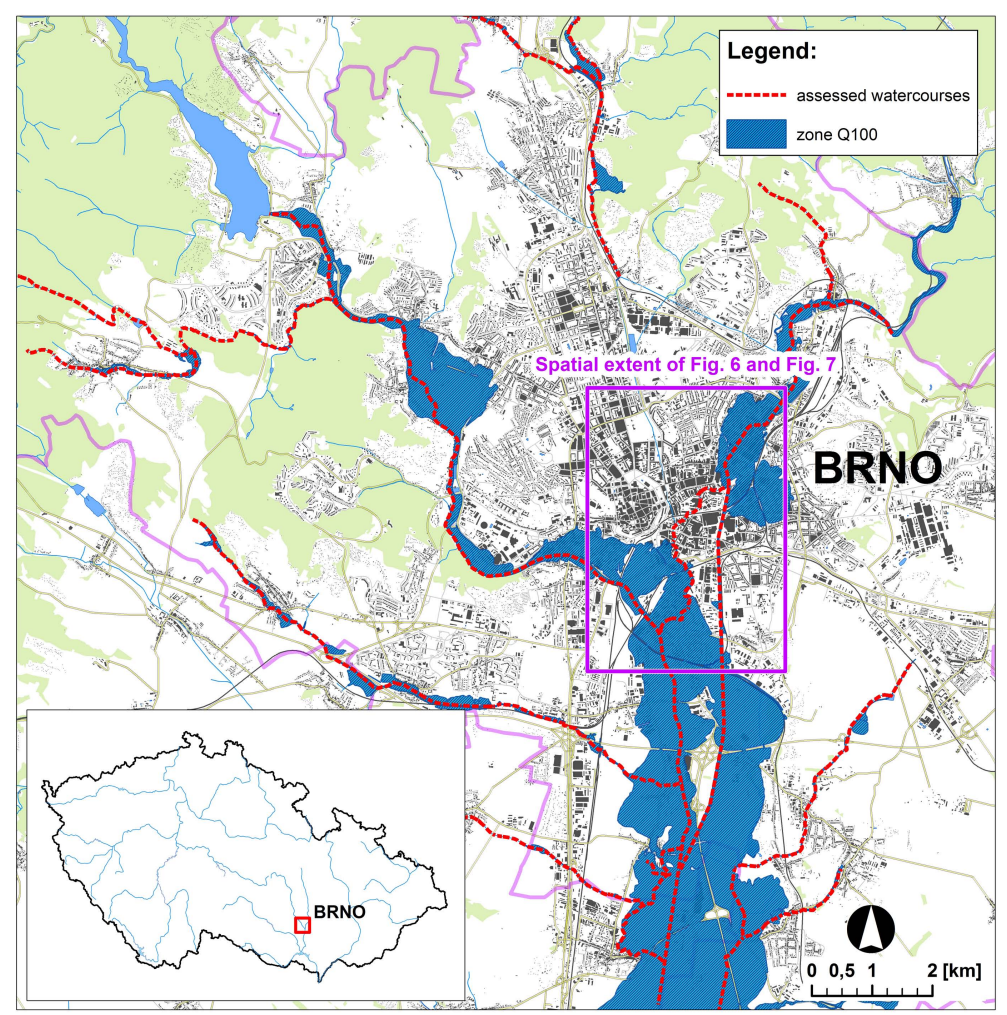

Fig. 5. Layout plan with assessed watercourses in the city of Brno.

are related to the following loss categories:

- $\mathrm{RI}_{1}$ - annual average loss - economic risk (see Eq. 6) (CZK/yr),

- $\mathrm{RI}_{2}$ - annual average affected population (inhabitants/yr),

- $\mathrm{RI}_{3}$ - annual average number of affected sensitive buildings (buildings/yr),

- $\mathrm{RI}_{4}$ - annual average affected area on which historical monuments are built $\left(\mathrm{m}^{2} / \mathrm{yr}\right)$,

- $\mathrm{RI}_{5}$ - annual average number of affected potential pollution sources (sources/yr).

Quantification of partial risk $\mathrm{RI}_{i}$ can be performed using the modified Eq. (6):

$\mathrm{RI}_{i}=\int_{0}^{p_{\mathrm{H}}} D_{i}(p) d p$,

where $\mathrm{RI}_{i}$ is the risk for loss category $i$ and $D_{i}(p)$ represents the functional dependence of corresponding potential loss on flood exceedance probability $p$.

For the MCA several techniques can be applied. For the MCA in the Czech Republic procedures based on the PROMETHEE II method (Brans and Mareschal, 2005) are currently being tested. A more detailed description of the theoretical aspects of particular MCA methods including PROMETHEE II is outside the scope of this paper; we refer the reader to available sources such as Brans and Mareschal (2005), Meyer et al. (2007).

\section{Case study}

The procedures mentioned above were applied in a flood risk management study which was part of the General Water Management Plan of the city of Brno (BCM, 2008). The study comprises of an assessment of 13 watercourses with a total length of about $87 \mathrm{~km}$ within the area of the city (Fig. 5), which has a population of over 400000 inhabitants. Part of the General Water Management Plan was the proposal of structural flood protection measures in the city of Brno based on hazard, danger and risk maps (Figs. 6 and 7).

The conceptual proposal for structural FPMs was implemented for the areas with exceeded levels of acceptable risk (see Sect. 2.2). For preliminary prioritisation purposes the system of FPMs in the urban area of Brno was divided into 28 sub-sections. The sub-sections were demarcated regarding their hydraulic independence and their relation to the flood protection measures in the sewer network.

To establish priorities for the progressive realization of FPM sub-sections the efficiency indicators defined by 


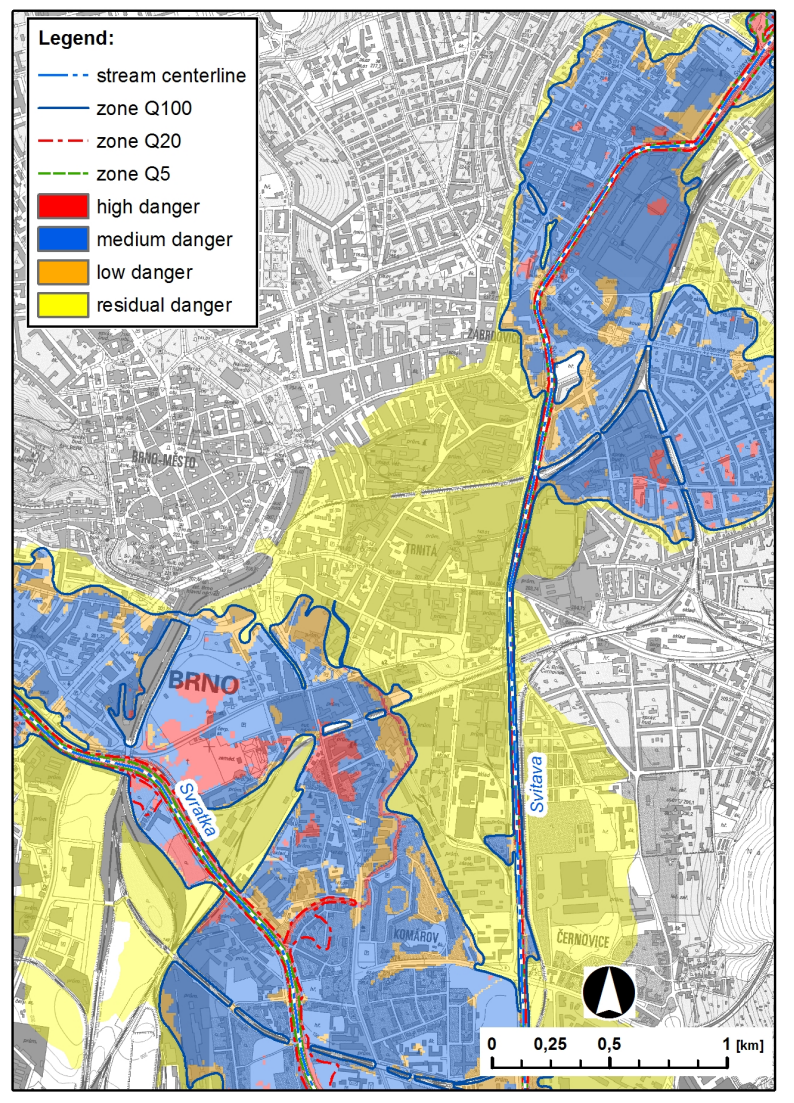

Fig. 6. Example of a flood danger map for the rivers Svratka and Svitava in Brno (original scale 1:10 000) (BCM, 2008).

Eqs. (7) and (8) were calculated for each sub-section. At this point, the aim was to assess partial risks in the sub-sections in terms of potential material losses. For the preliminary assessment the relative efficiency (RE) indicator was used, when FPMs at sub-sections for which $\mathrm{RE}<1$ were rejected as uneconomical. For those sub-sections with $R E \geq 1$ a descending sequence of FPMs ranked according to the value of RE figured out using Eq. (7) was elaborated. In cases when the $\mathrm{RE}$ ratings at consecutive sub-sections were approximately the same, the absolute efficiency AE was used as the second indicator. The resulting graphical interpretation is shown in Fig. 8.

Elaboration of detailed MCA study including sensitivity analysis is being anticipated in connection with the final decision regarding the priorities for flood protection measures in Brno.

\section{Conclusions and discussion}

In the paper the flood risk techniques corresponding to Flood Risk Directive 2007/60/EC of the European Parliament and of the Council on the assessment and management of flood risks are discussed in the context of implementing the Flood Risk Directive within the context of the conditions present

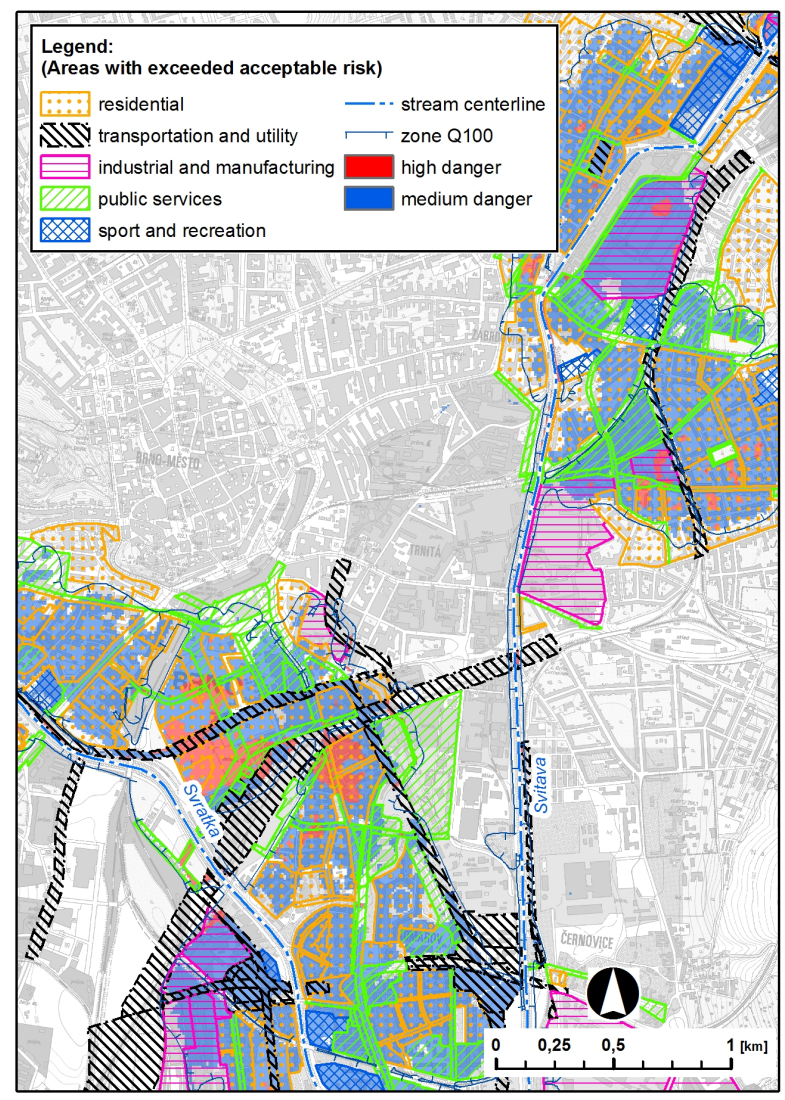

Fig. 7. Example of a flood risk map for the rivers Svratka and Svitava in Brno - areas with exceeded acceptable risk (original scale 1:10000) (BCM, 2008).

in the Czech Republic. The procedures used for the development of flood hazard and flood risk maps are described together with the solution of particular problems such as the development of danger and vulnerability maps or residual risk assessment. It was proposed that the assessment of economic efficiency, the application of which was demonstrated here in brief, should be a part of flood risk management plans.

The research shows that the present methods of flood risk analysis in the CR are generally in accordance with the Flood Risk Directive (ES, 2007). From this viewpoint, the Czech Republic is well-prepared for the implementation of the Flood Risk Directive, and long-term experience from research and numerous practical applications has recently been integrated into the Guidelines (MA CR, 2009) to the Flood Risk Directive (ES, 2007).

However, it must be stated that further research into flood risk analysis needs to be carried out to improve and refine individual techniques and outputs. It should be focused on the following topics related to the implementation of the Flood Risk Directive: 


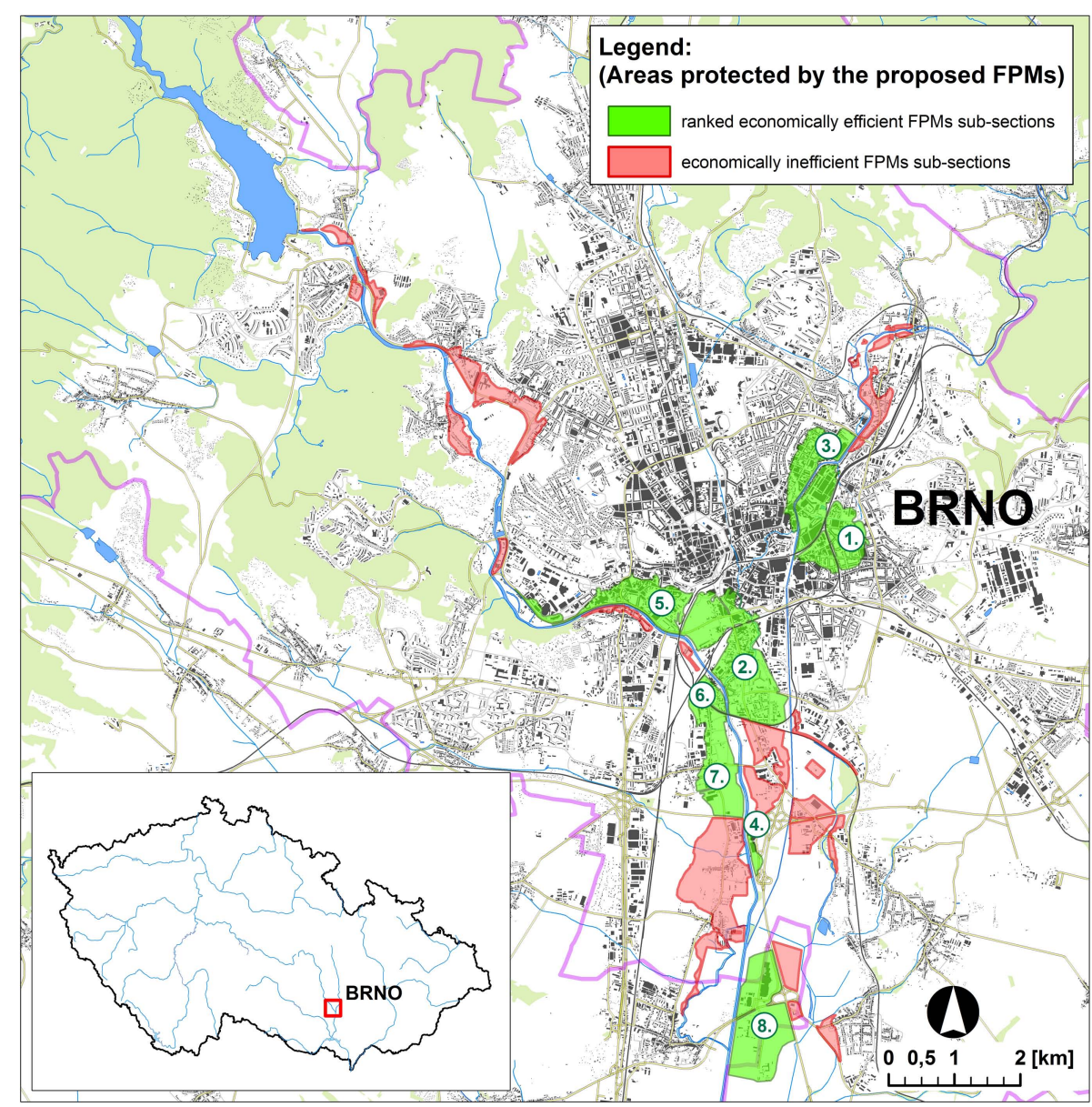

Fig. 8. Layout plan with ranked FPMs sub-sections in the city of Brno. Labels mean order of the corresponding FPM according the RE.

- more detailed multi-criteria flood risk assessment,

- non-structural flood protection measures and the evaluation of their effectiveness and efficiency,

- inclusion of risks from the exposure of inhabitants to flood hazards; the assessment of individual and societal risk,

- assessment of environmental risks, e.g. extensive water contamination due to the flooding of pollution sources,

- assessment of risks due to the flooding of sensitive facilities (social care institutions, hospitals, rescue services, police, etc.) and historical monuments,

- estimation of indirect losses,

- more comprehensive uncertainty analysis in risk management, including the effect of the influence of global changes on hydrological parameters.

From the point of view of technical structural arrangements the process culminates in the design and construction of risk attenuation measures, or alternatively measures for the maintenance of risk at an acceptable level. The proposals are assessed based on the comparison of the present risk level with the acceptable level. At present, quantitative risk analysis methods are dominantly based on the assessment of direct economic losses; the other aspects, such as human, social and environmental losses, are not taken into account in the Czech Republic. Therefore, the future endeavour will involve testing methods of multi-criteria flood risk assessment and their practical application.

Acknowledgements. The paper contains results from the research project of the Ministry of the Environment of the Czech Republic No. SP/1c2/121/07 "Flood risk maps in the Czech Republic" and from the project of Specific Research at Brno University of Technology No. FAST-S-10-24 "Impacts of flooding on people flood risk analysis". Part of this paper was presented at the WG F Thematic Workshop in Brno, Czech Republic on May 26, 2009. Furthermore, we thank the editor and anonymous reviewers for their pertinent comments.

Edited by: A. Günther

Reviewed by: J. Verkade and three other anonymous referees 


\section{References}

van Alphen, J. and Passchier, R.: Atlas of Flood Maps, examples from 19 European countries, USA and Japan, Ministry of Transport, Public Works and Water Management, The Hague, Netherlands, prepared for EXCIMAP, 2007.

BCM: Project report - General water management study, Watercourses - Risk analysis, Brno City Municipality, Brno, 2008.

Beffa, C.: A Statistical Approach for Spatial Analysis of Flood Prone Areas, International Symposium on Flood Defence, Kassel, Germany, 2000.

Brans, J. P. and Mareschal, B.: PROMETHEE methods, in: Multiple Criteria Decision Analysis: State of the Art Surveys, edited by: Figueira, J., Greco, S., and Ehrgott, M., Springer, New York, 2005, ISBN 0-387-23067-X, 163-195, 2005.

COSMC: Fundamental basis of geographical data (ZABAGED), Czech office for surveying, mapping and cadastre, Prague, available at: http://www.cuzk.cz (last access: 16 September 2010), 2009 (in Czech).

CSO: Census District and Building Register, Czech statistical office, Prague, available at: http://www.czso.cz/csu/rso.nsf/i/ registr_scitacich_obvodu (last access: 16 September 2010), 2009 (in Czech).

Drbal, K., Dràb, A., Ř́ha, J., et al.: The methods for determining flood risk and loss and their verification at the Elbe river basin, T. G. Masaryk Water Research Institute, Brno, Final report and guidelines No. VaV/650/5/02, 2006.

Drbal, K. and Štěpánková, P.: Preliminary Flood Risk Assessment in the Czech Republic, in: Das Magdeburger Gewässerschutzseminar 2008, Magdeburg, 97-99, 2008.

ES: Directive 2007/60/EC of the European Parliament and of the Council of 23 October 2007 on the assessment and management of flood risks, European Parliament, Council, 2007.

FOWM: Empfehlungen: Berücksichtigung der Hochwassergefahren bei raumwirksamen Tätigkeiten, EDMZ, CH-3000, Federal Office for Water Management, Bern, 1997.

Gouldby, B. and Samuels, P.: Language of Risk, FLOODsite Consortium, Report T32-04-01, available at: http://www.floodsite. net/ (last access: 16 September 2010), 2005.

Hutter, G.: Strategic Planning for Long-Term Flood Risk Management, IPS - International Planning Studies, 12(3), 273-289, 2007.

Klijn, F., Samuels, P., and Van Os, A.: Towards Flood Risk Management in the EU: State of affairs with examples from various European countries, International Journal of River Basin Management, 6(4), 307-321, 2008.

Kubal, C., Haase, D., Meyer, V., and Scheuer, S.: Integrated urban flood risk assessment - adapting a multicriteria approach to a city, Nat. Hazards Earth Syst. Sci., 9, 1881-1895, doi:10.5194/nhess9-1881-2009, 2009.

MA CR: Program documentation No. 129120 "Maintenance of flood prevention I", Ministry of Agriculture of the Czech Republic, Prague, 2006.
MA CR.: Guideline proposal for the creation of flood hazard and risk maps. T. G. Masaryk Water Research Institute, Brno. Ministry of Agriculture of the Czech Republic, Prague, available at: http://www.vuv.cz/oddeleni-gis/82/ dokumenty-ke-stazeni.html (last access: 16 September 2010), 2009.

Meyer, V., Scheuer, S., and Haase, D., et al.: GIS-based Multicriteria Analysis as Decision Support in Flood Risk Management, FLOODsite Consortium, Report T10-07-06, available at: http: //www.floodsite.net/ (last access: 16 September 2010), 2007.

Meyer, V., Scheuer, S., and Haase, D.: A multicriteria approach for flood risk mapping exemplified at the Mulde river, Germany, Nat. Hazards 48, 17-39, doi:10.1007/s11069-008-9244-4, 2009.

de Moel, H., van Alphen, J., and Aerts, J. C. J. H.: Flood maps in Europe - methods, availability and use, Nat. Hazards Earth Syst. Sci., 9, 289-301, doi:10.5194/nhess-9-289-2009, 2009.

MV CR: Act No. 254/2001 Sb. (Water Act), Ministry of Interior of the Czech Republic, Prague, available at: http://aplikace. mvcr.cz/archiv2008/sbirka/2001/sb098-01.pdf (last access: 16 September 2010), 2001 (in Czech).

MV CR: Decree No. 236/2002 Sb. regarding methods of floodplain documentation processing, Ministry of Interior of the Czech Republic, Prague, available at: http://aplikace.mvcr.cz/archiv2008/ sbirka/2002/sb089-02.pdf (last access: 16 September 2010), 2002.

Říha, J., Dráb, A., Jandora, J., et al.: Flood risk analysis, Monographs of the Water Structures Institute, FCE Brno University of Technology, CERM, 7, 286 pp., ISBN 80-7204-404-4, 2005.

Říha, J. and Dráb, A.: Implementation of Directive 2007/60/EC of the European parliament and of the Council on the assessment and management of flood risks in the Czech Republic, Working Group F on Floods, Thematic Workshop on Implementation of the Directive 2007/60/EC, Brno, 2009.

Samuels, P., Klijn, F., and Dijkman, J.: An analysis of the current practice of policies on river flood risk management in different countries, Irrig. Drain., 55, S141-S150, 2006.

Schanze, J., Hutter, G., Harries, T., Holzmann, H., Jessel, B., Koeniger, P., Kuhlicke, C., Meyer, V., Nachtnebel, H. P., Neuhold, C., Olfert, A., Parker, D., Penning-Rowsell, E., Schildt, A., and Werritty, A.: CRUE Research Report No I-1: Systematisation, evaluation and context conditions of structural and nonstructural measures for flood risk reduction, ERA-NET CRUE, FLOOD-ERA Joint Report, 2008.

T. G. M. WRI: Digital database of water management data (DIBAVOD), T. G. Masaryk Water Research Institute, Brno, available at: http://www.vuv.cz/oddeleni-gis/ (16 September 2010), 2009 (in Czech).

WGF: Work programme and mandate Working Group F for 2008-9, available at: http://ec.europa.eu/environment/ water/water-framework/objectives/implementation_en.htm (last access: 16 September 2010), 2007.

Zimmerman, M., Pozzi, A., and Stoessel, F.: Vademecum - Hazard Maps and Related Instruments, The Swiss System and its Application Abroad, PLANAT, Bern, Switzerland, 2005. 